Pacific Journal of Mathematics

AN OPERATOR ALGEBRA WHICH IS NOT CLOSED IN THE 


\title{
AN OPERATOR ALGEBRA WHICH IS NOT CLOSED IN THE CALKIN ALGEBRA
}

\author{
K. R. Davidson and C. K. Fong
}

\begin{abstract}
An example is constructed of an operator algebra which is closed in the weak operator topology but has a nonclosed image in the Calkin algebra.
\end{abstract}

Given a norm closed algebra of operators on Hilbert space, is the sum of this algebra with the ideal of all compact operators a closed set? The answer is well known to be yes for $C^{*}$-algebras [2]. It was shown by Arveson [1] to be closed for the discrete triangular algebra, and has recently been shown for all nest algebras by Muhly using his methods of [3]. Also, it is easily established for algebras of subnormal operators and Toeplitz operators. In this note, we will construct an algebra for which the sum is not closed. In fact, this algebra will be closed in the weak operator topology.

Let $\mathscr{A}$ be a norm closed algebra on a Hilbert space $\mathscr{H}$, let $\mathscr{L} \mathscr{C}$ denote the compact operators, and let $\pi$ denote the quotient map of $\mathscr{L}(\mathscr{X})$ onto the Calkin algebra $\mathscr{L}(\mathscr{H}) / \mathscr{L} \mathscr{C}$. It is apparent that $\mathscr{A}+\mathscr{L} \mathscr{C}$ is closed if and only if the image $\pi(\mathscr{A})$ is closed in the Calkin algebra. We will require the following elementary observation.

Proposition 1. If $\mathscr{A}$ is a norm closed subalgebra of $\mathscr{L}(\mathscr{H})$, then $\mathscr{A}+\mathscr{L} \mathscr{C}$ is closed if and only if $\mathscr{A} / \mathscr{A} \cap \mathscr{L} \mathscr{C}$ and $\pi(\mathscr{A})=$ $\mathscr{A}+\mathscr{L} \mathscr{C} \mid \mathscr{L} \mathscr{C}$ are isomorphic as Banach algebras.

CoROLlary 1. If $\mathscr{A}$ is a norm closed algebra such that $\mathscr{A}$ contains no compact operators except 0 , then $\mathscr{A}+\mathscr{L} \mathscr{C}$ is closed if and only if the quotient map $\pi$ is bounded below on $\mathscr{A}$.

The proof is a simple application of the Closed Graph Theorem.

Proposition 2. There is a (commutative) operator algebra A, closed in the weak operator topology, such that $\mathscr{A}+\mathscr{L} \mathscr{C}$ is not closed.

Proof. Let $\left\{e_{n}\right\}$ indexed on the integers be a basis for $\mathscr{H}$. Let $U$ be the bilateral shift defined by $U e_{n}=e_{n+1}$, and let $P$ be the one dimensional projection onto the span of $e_{0}$. Let $A=U+P$, and let $\mathscr{A}$ be the weakly closed algebra generated by $A$.

We will show that $\mathscr{A}$ does not contain any nonzero compact 
operators. Suppose $\mathscr{A}$ contains a compact operator $K$. Then we can find polynomials $p_{n}$ so that $p_{n}(A)$ tends to $K$ in the weak operator topology. The restriction of $p_{n}(A)$ to $\mathscr{K}$, the span of $\left\{e_{n} ; n \geqq 1\right\}$ is equal to the restriction of $p_{n}(U)$ to $\mathscr{K}$ which is unitarily equivalent to the Toeplitz operator of multiplication by $p_{n}$ on $H^{2}$ of the circle. Since the algebra of analytic Toeplitz operators is weakly closed, and no nonzero Toeplitz operator is compact, we conclude that $\left.p_{n}(A)\right|_{\text {r }}$ tends to zero in the weak operator topology. In particular we get that $\left(K e_{i}, e_{j}\right)=0$ for all $i \geqq 1$ and all $j$. Since the same is true for coanalytic Toeplitz operators and $\left.p_{n}\left(A^{*}\right)\right|_{\mathscr{C}}$, we note also that $\left(K e_{i}, e_{j}\right)=0$ for all $i$ and all $j \leqq 0$.

Furthermore, if we write $p_{n}(z)=\sum_{k} a_{k}^{(n)} z^{k}$, the fact that the Toeplitz operators for $p_{n}$ tend weakly to zero implies that for each $k$, $\lim _{n \rightarrow \infty} \alpha_{k}^{(n)}=0$. So, without loss of generality, we can assume that $a_{k}^{(n)}=0$ for $1 \leqq k \leqq N$ and all $n$. We notice that for $(i, j)$ belonging to the triangle $T_{N}$ :

$$
0 \geqq i \geqq-N, \quad 0 \leqq j \leqq N, \quad j-i \leqq N
$$

and for $m \geqq N$, we have $\left(A^{m} e_{i}, e_{j}\right)=1$. Hence $\left(p_{n}(A) e_{i}, e_{j}\right)$ is constant for $(i, j)$ in $T_{N}$. This must also hold in the limit, so $\left(K e_{i}, e_{j}\right)$ is constant for $(i, j)$ in $T_{N}$. But this $N$ was arbitrary, so $\left(K e_{i}, e_{j}\right)$ is constant on $i \leqq 0, j \geqq 0$. Since $K$ is a bounded operator, this must be zero. Together with the previous paragraph, we see that $K$ is zero.

However, $\left\|A^{n}\right\| \geqq \sqrt{n}$ and $\left\|\pi\left(A^{n}\right)\right\|=\left\|\pi\left(U^{n}\right)\right\|=1$, so $\pi$ is not bounded below on $\mathscr{A}$. Thus by Corollary $1, \mathscr{A}+\mathscr{L} \mathscr{C}$ is not closed.

COROLlaRY 2. There is a separable (commutative) norm closed algebra $\mathscr{B}$ such that $\mathscr{B}+\mathscr{L} \mathscr{C}$ is not closed.

Proof. Take $\mathscr{B}$ to be the norm closed algebra generated by $A$.

We would like to thank Eric Nordgren for some helpful discussions.

\section{REFERENCES}

1. W. B. Arveson, Interpolation problems in nest algebras, J. Functional Anal., 20 (1975), 208-233.

2. J. Dixmier, Les $C^{*}$-Algebres et Leur Representations, Gauthier-Villars, Paris, 1964.

3. R. I. Loebl and P. S. Muhly, Analyticity and flows in von Neumann algebras, to appear.

Received March 16, 1977. Research partially supported by U.S. National Science Foundation Grant MCS76-21044.

MassachusetTs INSTITUTE OF TEChNOLOGY

CAMbridge, MA 02139

AND

UNIVERSITY OF TORONTO

ToRonto, Canada 


\title{
PACIFIC JOURNAL OF MATHEMATICS
}

\author{
EDITORS
}

RICHARD ARENS (Managing Editor)

University of California

Los Angeles, California 90024

C. W. CurTis

University of Oregon

Eugene, OR 97403

C. C. MOORE

University of California

Berkeley, CA 94720
J. DUgundJI

Department of Mathematics

University of Southern Californı

Los Angeles, California 90007

R. Finn and J. Milgram

Stanford University

Stanford, California 94305

\section{ASSOCIATE EDITORS}

E. F. BECKENBACH

\section{SUPPORTING INSTITUTIONS}

\author{
UNIVERSITY OF BRITISH COLUMBIA \\ CALIFORNIA INSTITUTE OF TECHNOLOGY \\ UNIVERSITY OF CALIFORNIA \\ MONTANA STATE UNIVERSITY \\ UNIVERSITY OF NEVADA, RENO \\ NEW MEXICO STATE UNIVERSITY \\ OREGON STATE UNIVERSITY \\ UNIVERSITY OF OREGON \\ OSAKA UNIVERSITY
}

UNIVERSITY OF SOUTHERN CALIFORNIA

STANFORD UNIVERSITY

UNIVERSITY OF TOKYO

UNIVERSITY OF UTAH

WASHINGTON STATE UNIVERSITY

UNIVERSITY OF WASHINGTON
AMERICAN MATHEMATICAL SOCIETY
NAVAL WEAPONS CENTER 


\section{Pacific Journal of Mathematics \\ Vol. 72 , No. 1 \\ January, 1977}

Kazuo Anzai and Shiro Ishikawa, On common fixed points for several

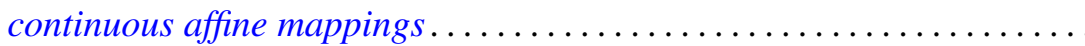

Bruce Alan Barnes, When is a representation of a Banach $*$-algebra

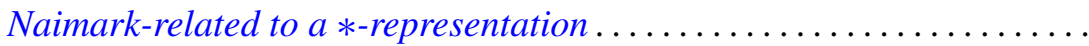

Richard Dowell Byrd, Justin Thomas Lloyd, Franklin D. Pedersen and

James Wilson Stepp, Automorphisms of the semigroup of finite

complexes of a periodic locally cyclic group ...................

Donald S. Coram and Paul Frazier Duvall, Jr., Approximate fibrations and a

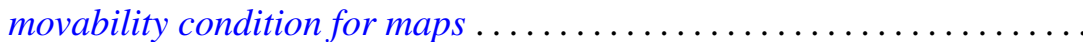

Kenneth R. Davidson and Che-Kao Fong, An operator algebra which is not

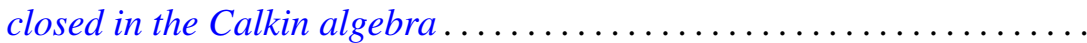

Garret J. Etgen and James Pawlowski, A comparison theorem and oscillation criteria for second order differential systems .............

Philip Palmer Green, $C^{*}$-algebras of transformation groups with smooth

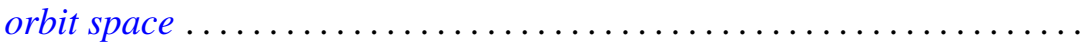

Charles Allen Jones and Charles Dwight Lahr, Weak and norm approximate

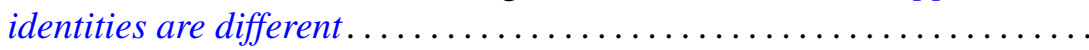

G. K. Kalisch, On integral representations of piecewise holomorphic

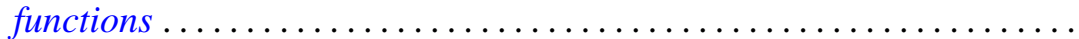

Y. Kodama, On product of shape and a question of Sher

Heinz K. Langer and B. Textorius, On generalized resolvents and

$Q$-functions of symmetric linear relations (subspaces) in Hilbert

space ...................................

Albert Edward Livingston, On the integral means of univalent, meromorphic functions

Wallace Smith Martindale, III and Susan Montgomery, Fixed elements of

Jordan automorphisms of associative rings ..........

R. Kent Nagle, Monotonicity and alternative methods for nonlinear boundary value problems ........................

Richard John O'Malley, Approximately differentiable functions: the $r$ topology.

Mangesh Bhalchandra Rege and Kalathoor Varadarajan, Chain conditions

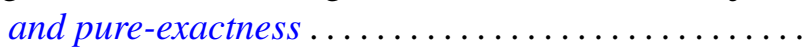

Christine Ann Shannon, The second dual of $C(X)$. .

Sin-ei Takahasi, A characterization for compact central double centralizers of $C^{*}$-algebras .

Theresa Phillips Vaughan, A note on the Jacobi-Perron algorithm. . .

Arthur Anthony Yanushka, A characterization of $\operatorname{PSp}(2 m, q)$ and

$\mathrm{P} \Omega(2 m+1, q)$ as rank 3 permutation groups ......... 